\title{
Prevalence of Urinary Incontinence in Women aged 20-59 years in Community Dwellings
}

\author{
Ratuafni Sharfina, ${ }^{1}$ Tina Dewi Judistiani, ${ }^{2}$ Amillia Siddiq ${ }^{3}$ \\ ${ }^{1}$ Faculty of Medicine Universitas Padjadjaran, ${ }^{2}$ Department of Public Health Faculty of Medicine \\ Universitas Padjadjaran, ${ }^{3}$ Department of Obstetrics and Gynecology Faculty of Medicine \\ Universitas Padjadjaran/Dr. Hasan Sadikin General Hospital, Bandung, Indonesia
}

\begin{abstract}
Background: Urinary incontinene (UI) is the symptomof involuntary leakage of urine. Three types of urinary incontinence are stress UI, urge UI, and mixed UI. This study was aimed to determine the prevalence of urinary UI in women and to identify the most common type of UI.

Methods: A descriptive study was conducted to 191 women age 20-59 in two villages in West Java, Indonesia. Subjects were visited door-to-door and interviewed using a standardized questionnaire for data collection. The study was conducted in February 2014. The variables of this study were age, parity, and the prevalence of urinary incontinence. The collected data were presented using frequency tabulation and percentage.

Results: From 191 respondents, thirty eight subjects had UI. The prevalence of urinary incontinence was $19.90 \%$ which consisted of prevalence of stress UI (7.33\%), urgency UI (9.43\%), and mixed UI (3.14\%). The prevalence of UI in 20-29 year age group was 3.23\%, 30-39 year age group was 9.72\%, 40-49 year age group was 27.69\%, and 50-59 year age group was 52.17\%. Prevalence of UI in nulliparous women was 5\%, primiparous was $10.25 \%$, multiparous with 2 childbirths was $23.61 \%$, and multiparous with 3 childbirths or more was $26.67 \%$.

Conclusions: Prevalence of UI in women in community dwelling is $19.90 \%$, which is higher than previous study from Indonesia and other Asian countries. Urgency UI is the most common type of UI. Prevalence of UI increases with age and parity.
\end{abstract}

Keywords: Community Dwellings, prevalence, urinary incontinence, women.

\section{Introduction}

International Continence Society (ICS) is defined urinary incontinence (UI) as symptomatic complaint of urinary leakage. ${ }^{1}$ Urinary incontinence is not a disease, but rather a symptom resulting from impairment of the bladder or of the sphincter. ${ }^{2}$ In Western societies, epidemiologic studies indicate a prevalence of urinary incontinence of 15 to 55 percent. This wide range is attributed to variations in research methodologies, population characteristics, and definitions of incontinence. ${ }^{3}$

According to The Asia Pacific Continence Board (APCB), UI prevalence is $20.9-35 \%$ where UI is more prevalent in women $(15.1 \%)$ compared to men (5.8\%). From those women with UI, $24.9 \%$ have stress UI, $10.5 \%$ have urgency UI, and $5 \% .{ }^{4}$ Overall prevalence of UI in Indonesia ${ }^{5}$ is $13 \%$ and it increases with age. ${ }^{2,6}$ Stress UI is the most common type UI in women, meanwhile urgency UI is more common in older women. ${ }^{1}$

The UI can significantly impair women's quality of life, leading to disrupted social relationships, psychological distress from embarrassment and frustration, hospitalizations due to skin breakdown and urinary tract infection, and sleep disorder. ${ }^{3,6}$ Women with stress UI find a way to cope with incontinence by limiting their daily activities. Limiting their activities may eliminate the incontinence problem, but it does so at a certain cost to their quality of life. ${ }^{1}$ This study was conducted to determine the prevalence of UI and to identify the most common type of UI in women aged 20-59 years in community dwellings.

Correspondence: Ratuafni Sharfina, Faculty of Medicine, Universitas Padjadjaran, Jalan Raya Bandung-Sumedang Km.21, Jatinangor, Sumedang, Indonesia, Phone: :+6281908428625 Email: ratuafnisharfina@yahoo.com 


\section{Methods}

This descriptive study was conducted in February 2014 to women who lived in two villages (Mekargalih and Cipacing) in Jatinangor, West Java, Indonesia. This study was part of the study project by Midwifery Program, Faculty of Medicine, Universitas Padjadjaran.

Inclusion criteria were women aged 20-59 years old and registered as a resident in Mekargalih or Cipacing village during data collection. Exclusion criteria included women who were pregnant, women who could not speak, women who could not speak Indonesian, women with dementia and/ or women who had a mental disorder. After given some explanation about this study, the respondents who were willing to participate in this study were asked to sign a written consent form.

Sample size was calculated using descriptive study formula ${ }^{7}$

$n=\frac{Z^{2} \times p \times(1-p)}{e^{2}}$

which was valid where $\mathrm{n}$ is the sample size, $\mathrm{Z} \alpha$ was the abscissa of the normal curve that cut off an area at the tail (1.96), p was the estimated propotion of an attributed that presented in the population $(13 \%)$, and e was the desired level of precision (5\%).

The number of sample was 174 respondents. Respondents were selected by simple random sampling of Mekargalih village and Cipacing village family cards data. The visits were conducted with door-to-door method in accordance with the list of respondents and then, the guided interviews with respondents who were eligible to use QUID (Questionnaire for Urinary Incontinence Diagnosis) ${ }^{8}$ were conducted. Urinary Incontinence (UI) defined as urinary complaints that happened accidentally or involuntarily for 7 days was divided into 3 types, which were stress, urgency, and mixed. ${ }^{3,6}$ Stress UI is the process of involuntary urination during coughing, sneezing, or other physical activities that increase intra-abdominal pressure. Urgency UI is characterized by involuntary urination which is preceded by a strong desire to urinate/ urgency. Mixed UI is the simultaneous presence of stress UI and urgency UI complaints. ${ }^{1,3,6}$

The QUID is a short valid and responsive instrument that can serve as a diagnostic tool to determine UI type and also as a mesure of stress \& urgency UI. There were 6 questions, the first 3 items focused on stress
UI symptoms and other 3 items focused on urgency UI symptoms. First 3 items in the questionnaire asked if the respondents experienced incontinence when coughing/ sneezing, bending down/lifting something up, and walking quickly/jogging/exercising. The rest of the items asked if the respondents experienced incontinence when undressing in order to go to toilet, having a strong and uncomfortable need to urinate that the urine leaked before reaching to the toilet, and having to rush to the bathroom because of a sudden and strong need to urinate. Each question had 6 response options ranging from none of the time (score 0 point), rarely (score 1 point), once in a while (score 2 points), often (score 3 points), most of the time (score 4 points), all of the time (score 5 points).

Permission to conduct this study was given by the Health Research Ethics committee of the Faculty of Medicine, Universitas Padjadjaran, BAPPEDA Sumedang and Jatinangor subdistrict office. The data were then analyzed using statistics program.

\section{Results}

There were 191 respondents who met the inclusion criteria and were willing to answer the questionnaire in the interview. The majority were between 30-39 years old (37.70\%).

The majority of the respondents were multiparous which were $37.70 \%$ who had given birth twice and $31.41 \%$ who had given birth $\geq 3$ times.

Table 3 describes the prevalence of UI. Among 191 respondents, there were 38 respondents who had UI. The prevalence of all types of UI was $19.90 \%$. The prevalence of stress UI was $7.33 \%$ (14 respondents), urgency UI was $9.43 \%$ (18 respondents) and mixed UI was 3.14\% (6 respondents).

The percentage of UI tends to be higher with higher age category. The lowest prevalence was the age category of 20-29 years old. The highest prevalence was the age category of 50-59 years old which was $52.17 \%$ and $34.78 \%$ of who were suffering from urgency UI. The prevalence of stress UI increased with age while the prevalence of mixed UI did not increase with age.

Among the respondents who were nullipara, only $5 \%$ of them had UI. However, among primiparous respondents, the prevalence of UI was two-fold, which was $10.25 \%$. Multiparous was divided into who had given birth twice and more than or equal to 3 times. The prevalence 
Table 1 Characteristics of Respondents based on Age and Parity

\begin{tabular}{lcc}
\hline \multicolumn{1}{c}{ Characteristic } & Frequency & $\%$ \\
\hline Age (years) & & \\
$20-29$ & 31 & 16.23 \\
$30-39$ & 72 & 37.70 \\
$40-49$ & 65 & 34.03 \\
$50-59$ & 23 & 12.04 \\
Parity & & \\
0 & 20 & 10.47 \\
1 & 39 & 20.42 \\
2 & 72 & 37.70 \\
$\geq 3$ & 60 & 31.41 \\
\hline
\end{tabular}

on respondents who had given birth twice reached $23.61 \%$ with stress, urgency, and combination UI respectively, $9.72 \%, 11.11 \%$, and $2.78 \%$. The prevalence on respondents who had given birth more than or equal to 3 times was $26.67 \%$.

\section{Discussion}

Overall, the prevalence of UI in this study was $19.90 \%$, higher than previous hospital based-study in Indonesia by Sumardi et al. ${ }^{5}$ that is $13 \%$. Yet, UI prevalence in this study was similar to previous community dwelling study about prevalence of UI in women aged 20-59 years in Taiwan9 (18.7\%). This difference could be caused by variation in population characteristic, tool for data collection, or research methodologies. The community dwelling study showed a higher prevalence than the hospital based-study. As the developing country where poverty is still a main problem, quality of life is not a concern for most Indonesian people. In addition, from the patient's point of view, UI remains a taboo subject. ${ }^{10}$ Study in Taiwan ${ }^{11}$ found that the main reason women do not seek a medical treatment for UI is shyness. This may explain its higher prevalence of UI in population-based study than in the hospital-based study.

In this study, the most prevalent type of UI was the urgency type. This result was different with findings from Western countries and The Asia Pacific Continense Board (APCB) stating that stress UI is the most prevalent. ${ }^{4}$ The prevalence of urgency UI in this study was $9.43 \%$, similar to study conducted by Milsom etc in 2013 that found the prevalence of urgency UI in Indonesia was $8 \%{ }^{12}$ The prevalence of stress UI and mixed UI in this study was $7.33 \%$ and $3.14 \%$, respectively, similar to the prevalence of stress UI and mixed UI in Indonesia which is 5.1\% and 1.6\%, respectively. ${ }^{5}$

Very few studies and data were available about urgency UI in Indonesia. Meanwhile, the prevalence of urgency IU was predicted

Table 2 Classification of Urinary Incontinence (UI)

\begin{tabular}{lcc}
\hline \multicolumn{1}{c}{ Types of Urinary Incontinence } & f & \% \\
\hline Stress UI & & \\
$\quad$ QUID score stress $\geq 4$ & 14 & 7.33 \\
Urgency UI & 18 & \\
$\quad$ QUID score urgency $\geq 6$ & & 9.43 \\
Mixed UI & 6 & 3.14 \\
$\quad$ QUID score stress $\geq 4 \&$ QUID score urgency $\geq 6$ & 38 & 19.90 \\
Overall prevalence of UI &
\end{tabular}


Ratuafni Sharfina, Tina Dewi Judistiani, Amillia Siddiq: Prevalence of Urinary Incontinence in Women aged 181 20-59 years in Community Dwellings

Table 3 Prevalence of Urinary Incontinence (UI) by Age Category

\begin{tabular}{|c|c|c|c|c|c|}
\hline \multirow{2}{*}{$\begin{array}{l}\text { Age Category } \\
\text { (years old) }\end{array}$} & \multirow{2}{*}{ N (\%) } & \multirow{2}{*}{$\begin{array}{c}\text { UI } \\
\text { n(\%) }\end{array}$} & \multicolumn{3}{|c|}{ Types n(\%) } \\
\hline & & & Stress & Urgency & Mixed \\
\hline $20-29$ & 31 (16.23\%) & $1(3.23 \%)$ & $0(0 \%)$ & $1(3.23 \%)$ & $0(0 \%)$ \\
\hline $30-39$ & $72(37.70 \%)$ & 7 (9.72\%) & $4(5.56 \%)$ & $3(4.17 \%)$ & $0(0 \%)$ \\
\hline $40-49$ & 65 (34.03\%) & $18(27.69 \%)$ & $7(10.77 \%)$ & $6(9.23 \%)$ & $5(7.69 \%)$ \\
\hline $50-59$ & $23(12.04 \%)$ & $12(52.17 \%)$ & $3(13.04 \%)$ & 8 (34.78\%) & $1(6.78 \%)$ \\
\hline
\end{tabular}

to increase to $25 \%$ in the next decade due to the aging population. Increased prevalence of urgency IU and its morbidity became an economic burden to society and personal burden for the patient as an individual. Additional costs included cost for laundry, panty liner/pad, and the cost for treatment due to comorbidity of UI like urinary tract infection. ${ }^{12}$ Lack of awareness of UI patients in Indonesia caused comorbidity sufferred becomes more likely and bigger economic burden. Public health programs and clinical management of patients are needed to raise the awareness of UI patients and health workers.

Based on age, the prevalence of UI increases with age. The prevalence of UI in the respondents aged 40-49 years was 27.69\%. The highest prevalence was $52.17 \%$ in respondents aged 50-59 years. These results were consistent with findings by Hannestad ${ }^{3}$, which the prevalence of UI in women aged $30-39$ years ranges between $18.2-21.2 \%$. This result was not similar to findings by Ghafouri et al. ${ }^{13}$ in Qatar that found the highest prevalence of UI in women aged 40-49 years old, which is $29.2 \%$ and prevalence of UI in women aged $50-59$ years old decrease to $21.9 \%$.

In this study, prevalence of stress UI and urgency UI in women aged 30-39 years old were $5.56 \%$ and $4.17 \%$, respectively. The prevalence of stress UI was $10.77 \%$, urgency UI was $9.23 \%$, and mixed UI was $7.69 \%$ in women aged 40-49 years old. The prevalence of stress UI was $13.04 \%$, urgency UI was $34.78 \%$, and mixed UI was $6.78 \%$ in women aged $50-59$ years old. These findings were consistent with available evidence that indicates urgency UI is a highly prevalent condition among men and women worldwide, particularly those aged $\geq 40$ years old. ${ }^{12}$

This study found an increase prevalence of stress and urgency UI with age, particularly urgency UI and decrease prevalence of mixed UI with age. Similar results were also found by Botlero et al. ${ }^{14}$ who found that the increasing age is significantly associated with urgency UI but not with stress and mixed UI.

Table 4 showed an overall prevalence of UI and its type based on parity. The parity was defined as $0,1,2$, and $\geq 3$. Overall, the prevalence of UI increased with parity. The prevalence of UI was 5\% in nulliparous women, $10.25 \%$ in primiparous women, $23.61 \%$ in multiparous women with 2 childbirths, and $26.67 \%$ in multiparous women with 3 childbirths or more. This is consistent with many studies that suggest that prevalence of UI is higher in multiparous women compare to nulliparous women. The effects of childbirth on incontinence may result from direct trauma to the pelvic muscles and connective tissue of the pelvic floor. Approximately $20 \%$ of women who had a vaginal deliveryshows a visible defect on levator ani muscle. ${ }^{1,3}$

Prevalence of stress UI in this study increases with parity, similar results were also found by Botlero et al. ${ }^{14}$. Prevalence of stress UI in primiparous women was $5.13 \%$, then increases to $9.72 \%$ in multiparous women

Table 4 Prevalence of Urinary Incontinence (UI) based on Parity

\begin{tabular}{lccccc}
\hline \multirow{2}{*}{ Parity } & n (\%) & Incontinence & \multicolumn{3}{c}{ Types n (\%) } \\
\cline { 4 - 6 } & & $\mathbf{n ( \% )}$ & Stress & Urgency & Mixed \\
\hline 0 & $20(10.47 \%)$ & $1(5 \%)$ & $0(0 \%)$ & $1(5 \%)$ & $0(0 \%)$ \\
1 & $39(20.42 \%)$ & $4(10.25 \%)$ & $2(5.13 \%)$ & $2(5.13 \%)$ & $0(0 \%)$ \\
2 & $72(37.70 \%)$ & $17(23.61 \%)$ & $7(9.72 \%)$ & $8(11.11 \%)$ & $2(2.78 \%)$ \\
$\geq 3$ & $60(31.41 \%)$ & $16(26.67 \%)$ & $5(8.33 \%)$ & $7(11.67 \%)$ & $4(6.67 \%)$ \\
\hline
\end{tabular}


with 2 childbirths. The prevalence of stress UI in multiparous women with 3 childbirths or more was $8.33 \%$. This results were similar to findings by Danforth et al. ${ }^{15}$ who found that the first 2 births account for most of the effects.

The prevalence of urgency UI increased with parity that contradicted the findings by Botlero et al. ${ }^{14}$ i.e parity is not associated with urgency UI. It could be explained by the characteristics of the most multiparous women in this study which were particularly those with 3 childbirths or more, older than nulliparous women. The prevalence of mixed UI increased in multiparous women, which was $2.78 \%$ in women with 2 childbirths and $6.67 \%$ in women with 3 childbirths or more. Similar results were also found in China ${ }^{16}$.

In this study, the prevalence of UI in nulliparous women was $5 \%$ and all of them were women with urgency UI. The prevalence of UI in women aged 20-29 years old was $3.23 \%$ and all of them were women with urgency UI. Urge incontinence not infrequently occurs with acute cystitis, particularly in women. ${ }^{17}$ Urinary tract infection also may exacerbate symptom of incontinence. ${ }^{1}$ Further anamnesises are needed to identify other symptoms of urinary tarct infection (frequency and dysuria). The diagnosis of urinary tract infection relies on urinalysis and urine culture. The urine is evaluated for leukocyte esterase by a urine dipstick and microscopic examination for WBCs and bacteria. ${ }^{18}$ Routine microscopic examination is available in Jatinangor primary health care, but urinalysis to evaluate leukocyte esterase is not yet available.

From public health's point of view, it is important to identify risk factors for UI. Identification of risk factors will help in lifestyle behavior modification of women at risk, which will be important for prevention of UI. ${ }^{19}$ Conservative therapy pelvic muscle floor training (kegel exercise) is a reasonable initial approach to most patients with urinary incontinence. ${ }^{3}$ It is easy and very likely to be held in primary health care. The Cochrane Incontinence Group concluded that pelvic floor muscle training is consistently better than no treatment or placebo treatment for stress incontinence and should be offered as first-line conservative management to women. Medical evidence from welldesigned randomized clinical trials shows that supervised kegel exercise is an effective treatment for stress UI. ${ }^{1}$ Studies have shown up to $70 \%$ improvement in symptoms of stress UI following appropriately pelvic floor muscle exercises. This improvement is the evident across all age groups. ${ }^{20}$ For urge urinary incontinence, it improves pelvic floor muscle contractions strength to provide temporary continence during waves of bladder detrusor contraction. ${ }^{3}$ Subspeciality Urogynecology in Department of Obstetric and Gynecology at Dr. Hasan Sadikin General Hospital Bandung provides a comprehensive management for UI.

There were some limitations in this study. This study was conducted using descriptive design making this study could not analyze the cause and effect relationship between age, parity, and prevalence of UI.

In conclusion, overall prevalence of UI in women in Jatinangor subdistrict is $19.90 \%$, higher than previous study in Indonesia and other Asian countries. Of $19.90 \%$ women with UI, $9.43 \%$ have urgency UI, $7.33 \%$ have stress UI, and $3.14 \%$ have mixed UI. These findings may increase the awareness of UI and its burden in population. Further identifications of risk factors and measurement of public health burden are needed to determine the appropriate public health and clinical management program. The prevalence of UI increases with age, particularly urgency UI, while the prevalence of UI increases with parity.

\section{References}

1. Nygaard I, Menefee SA, Wall LL. Lower urinary tract disorder. Berek \& novak's gynecology. Philadelphia: Lippincott Williams \& Wilkins; 2007. p. 849-96.

2. Kwon BE, Kim GY, Son YJ, Roh YS, You MA. Quality of life of women with urinary incontinence : a systematic literature review. Int Neurourol J. 2010;14(3):133-8.

3. Hoffman B, Schorge J, Schaffer J, Halvorson L, Bradshaw K, Cunningham F. Urinary incontinence. Williams gynecology. 2nd ed. Dallas: The McGraw-Hill Companies, Inc.; 2012. p. 606-30.

4. Suparman E, Rompas J. Urinary incontinence in postmenopausal women. Maj Obstet Ginekol Indones. 2011;32(1):48-54.

5. Sumardi R, Mochtar CA, Junizaf, Santoso BI, Setiati S, Nuhonni SA, et al. Prevalence of urinary incontinence, risk factors and its impact: multivariate analysis from Indonesian nationwide survey. Acta Med Indones. 2014;46(3):175-82.

6. Santoso BI. Urinary Incontinence in Female Patients. Maj Kedokt Indon. 2011;58(07):258-64.

7. Kasiulevičius V, Šapoka V, Filipavičiūtė R. 
Sample size calculation in epidemiological studies. Gerontologija. 2006;7(4):225-31.

8. Bradley CS, Rahn DD, Nygaard IE, Barber MD, Nager CW, Kenton KS, et al. The questionnaire for urinary incontinence diagnosis (QUID): Validity and responsiveness to change in women undergoing non-surgical therapies for treatment of stress predominant urinary incontinence. Neurourol Urodyn. 2010;29(5):727-34.

9. Hsieh C-H, Su T-H, Chang S-T. Prevalence of and attitude toward urinary incontinence in Taiwanese women. Int J Gynaecol Obstet. 2005;88(2):152-3.

10. Cornu J. Urinary incontinence symptoms stratification: the devil Is in the details. Eur Urol. 2012;61(1):96-7.

11. Hsieh C-H, Su T-H, Chang S-T, Lin S-H, Lee M-C, Lee MY. Prevalence of and attitude toward urinary incontinence in postmenopausal women. Int J Gynaecol Obstet. 2008;100(2):171-4.

12. Milsom I, Coyne KS, Nicholson S, Kvasz M, Chen C-I, Wein AJ. Global prevalence and economic burden of urgency urinary incontinence: a systematic review. Eur Urol. 2014;65(1):79-95.

13. Ghafouri A, Alnaimi AR, Alhothi HM, Alroubi I, Alrayashi M, Molhim NA, et al. Urinary incontinence in Qatar: A study of the prevalence, risk factors and impact on quality of life. Arab J Urol. 2014;12(4):269-
74.

14. Botlero R, Davis SR, Urquhartb DM, Shortreedb S, Bell RJ. Age-specific prevalence of, and factors associated with, different types of urinary incontinence in community-dwelling Australian women assessed with a validated questionnaire. Maturitas. 2009;62(2):134-9.

15. Danforth K, Townsend M, Lifford K, Curhan G, Resnick N, Grodstein F. Risk factors for urinary incontinence among middle-aged women. Am J Obstet Gynecol. 2006;194(2):339-45.

16. Zhu L,Li L, LangJ,Xu T,WongF.Epidemiology of mixed urinary incontinence in China. Int J Gynaecol Obstet. 2010;109(1):55-8.

17. McAninch J. Symptom of disorders of genitourinary tract. Smith's general urology. 17 ed. California: The McGrawHill Companies, Inc; 2008. p. 30-8.

18. Nguyen H. Bacterial infections of the genitourinary tract. Smith's general urology. 17th ed. California: The McGrawHill Companies, Inc; 2008. p. 193-218.

19. Hsieh C-H, Lee M-S, Lee M-C, Kuo T-C, Hsu C-S, Chang S-T. Risk s for urinary incontinence in Taiwanese women aged 20-59 years. Taiwan J Obstet Gynecol. 2008;47(2):197-202.

20. Price N, Dawood R, Jackson SR. Pelvic floor exercise for urinary incontinence: A systematic literature review. Maturitas. 2010;67(4):309-15. 